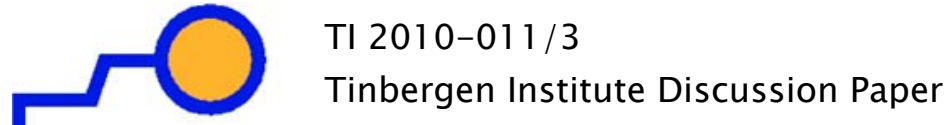 \\ Enhanced Cooperation in an Asymmetric Model of Tax Competition
}

Hendrik Vrijburg ${ }^{1,2}$

Ruud A. de Mooiji,2,3,4,5

1 Erasmus University Rotterdam;

2 Tinbergen Institute;

${ }^{3} \mathrm{CPB}$;

${ }^{4}$ CESifo;

${ }_{5}^{5}$ Oxford University Centre for Business Taxation. 


\section{Tinbergen Institute}

The Tinbergen Institute is the institute for economic research of the Erasmus Universiteit Rotterdam, Universiteit van Amsterdam, and Vrije Universiteit Amsterdam.

Tinbergen Institute Amsterdam

Roetersstraat 31

1018 WB Amsterdam

The Netherlands

Tel.: +31(0)205513500

Fax: $+31(0) 205513555$

Tinbergen Institute Rotterdam

Burg. Oudlaan 50

3062 PA Rotterdam

The Netherlands

Tel.: + $31(0) 104088900$

Fax: $+31(0) 104089031$

Most TI discussion papers can be downloaded at http://www.tinbergen.nl. 


\title{
Enhanced Cooperation in an asymmetric model of Tax Competition
}

\author{
Hendrik Vrijburg*and Ruud A. de Mooij ${ }^{\dagger}$ \\ Erasmus University Rotterdam
}

31 December 2009

\begin{abstract}
This paper analyzes enhanced cooperation agreements in corporate taxation in a three country tax competition model where countries differ in size. We characterize equilibrium tax rates and the optimal tax responses due to the formation of an enhanced cooperation agreement. Conditions for strategic complementarity or strategic substitutability of tax rates are crucial for the welfare effects of enhanced cooperation. Simulations show that enhanced cooperation is unlikely to be feasible for small countries. When enhanced cooperation is feasible, it may hamper global harmonization. Only when countries are of similar size is global harmonization a feasible outcome.
\end{abstract}

JEL codes: E62, F21, H25, H77

Keywords: Tax coordination; Asymmetry; Enhanced Cooperation Agreements; Strategic Tax Response.

\section{Introduction}

Although European tax harmonization has been debated ever since the European Economic Community was established, Europe has never been successful in any serious cooperation in corporate taxation. Yet, the economic arguments for such cooperation are strong. For instance, cooperation could improve efficiency due to smaller distortions in the international allocation of capital and prevent an underprovision of public goods associated with a race to the bottom in tax rates. These benefits of cooperation, however, seem asymmetrically distributed across countries (see e.g. Sørensen (2004)). Some countries might actually be

${ }^{*}$ Tinbergen Institute, Faculty of Economics, Erasmus University Rotterdam, P.O. Box 1738, 3000 DR Rotterdam, The Netherlands. Phone: +31-10-408-2524, Fax: +31-10-408-9031, E-mail: vrijburg@ese.eur.nl

${ }^{\dagger}$ Erasmus University Rotterdam, Tinbergen Institute, CPB, CESifo and Oxford University Centre for Business Taxation. E-mail: demooij@ese.eur.nl 
worse off from tax harmonization relative to tax competition. In light of unanimity voting, this impedes any agreement between all Member States.

The Treaty of the European Union offers a way out of this status quo in the form of enhanced cooperation agreements (ECAs). An ECA occurs if not all 27 Member States agree upon cooperation, but a subgroup (or coalition) among them (with a minimum of eight). ECAs have been institutionalized in Europe by the treaties of Amsterdam (1997) and Nice (2003) and must comply with a number of rules. For instance, the ECA can only be used when attempts to unify all Member States have failed, it should be authorized by the European Council following a qualified majority vote, and it remains open for all Member States at all times.

The formation of an ECA with respect to corporate taxes raises several questions. For example, how will tax rates inside and outside the ECA change? How will the ECA affect welfare in participating and non-participating countries? When will ECA countries decide to opt in? When do insider countries find it attractive to allow them in? Can the ECA be regarded as a first step towards full harmonization or will it introduce a status-quo bias which frustrates global harmonization?

There is a small theoretical literature exploring these questions 1$]$ As a strating point, Burbidge, DePater, Myers and Sengupta (1997) study the endogenous formation of coalitions and outline that prospective members of an ECA must agree on: (i) a common policy; (ii) a formula for dividing the surplus from cooperation, and; (iii) the preferred coalition partners. Only when countries sufficiently similar, will a grand coalition of all countries arise in equilibrium.

Otherwise, a smaller coalition is formed for a number of reasons. First, an ECA arises when a small coalition extracts surplus from outsiders. Burbidge et al. (1997) proof this proposition in a asymmetric tax competition model. Riedel and Runkel (2007) apply this argument to an ECA stipulating a common consolidated corporate tax base with formula apportionment. This ECA achieves a positive surplus from cooperation due to reduced profit

\footnotetext{
${ }^{1}$ Besides the theoretical contributions mentioned, enhanced cooperation in corporate taxation is studied in computable general equilibrium models by a number of authors, see Sørensen (2000, 2004), Brøchner, Jensen, Svensson and Sørensen (2006) and Bettendorf, van der Horst, de Mooij and Vrijburg (2009).
} 
shifting towards outsider countries. Second, a two-way conflict of interest might arise in case of heterogeneous preferences (Alesina, Angeloni, Etro (2005)). The common policy decided on by ECA members reflects the preference of these members. Prospective members have to trade-off the benefits from cooperation against the cost of aligning its policy with the common ECA policy. Some prospective members prefer to stay outside the coalition, which also pleases those insiders with rather different preferences. Third, in case the benefits of cooperation are uncertain an ECA between countries with more or less similar policies can serve as a pilot coalition. Countries with similar policies can reap the benefits from cooperation at relative low cost. Bordignon and Brusco (2006) apply this argument to corporate tax base harmonization.

However, caution is required in stimulating ECAs. First, ECAs will be reluctant to accept newcomers if these newcomers intend to change the ECA policies. This is labeled the status quo bias: the original ECA influences further harmonization initiatives (Alesina et al. (2005) and Bordignon and Brusco (2006)). Second, when excluding prospective members is prohibited or difficult, the formation of an ECA might fail if the surplus of cooperation vanishes beyond a particular ECA size. Manzini and Mariotti (2002) label this phenomenon a tragedy of the clubs.

With respect to the welfare implications of ECAs, Beaudry, Cahuc and Kempf (2000) find that, in a symmetric model, the formation of ECAs is welfare improving if spillovers within the ECA are of the same sign as the spillovers between the ECA and the rest of the world. In this case, the common policy by the ECA, which internalizes within ECA spillovers, benefits outsiders. Applied to a symmetric capital tax competition model, Konrad and Schjelderup (1999) add to this prescription the requirement that the policy of the ECA and the outsider countries should be strategic complements.

This paper generalizes the analysis of Konrad and Schjelderup (1999) by allowing asymmetry in country size. To that end, we extend the model of Bucovetsky (1991) and Wilson (1991) with a third country. This yields a variety of new insights. Moreover, some key results in standard tax competition models regarding the impact of global tax harmonization do not carry over to partial tax harmonization in a subset of countries. 
We find that countries always set higher tax rates under an ECA than under tax competition. The response by the country that remains outside the ECA is ambiguous. We derive analytical conditions for its tax rate to be a strategic complement or a strategic substitute. Strategic complementarity, which is assumed in Konrad and Schjeldrerup, is not at all guaranteed, especially when the outsider country is large. Strategic complementarity is necessary for an ECA to be welfare improving for all countries. An ECA is more feasible in terms of welfare than global harmonization when countries are sufficiently different in size. Under strategic substitutability, however, the feasibility of an ECA depends on whether the ECA countries act as Stackelberg leader or play Nash. The opportunity to form an ECA may impede global harmonization and thus introduce a status-quo bias, even though global harmonization would have been welfare improving for all countries compared to tax competition.

The rest of the paper is organized as follows. Section (2) introduces the three-country model. Section (3) characterizes the optimal tax rates under four different regimes. Section (4) discusses tax reactions across countries and analytically derives conditions for tax rates to be strategic complements. Section (5) illustrates the global properties of equilibrium tax rates for different size configurations and under different regimes regarding tax setting. Section (6) simulates the welfare effects in the associated equilibria. Finally Section (7) concludes.

\section{A three-country model of tax competition}

Consider three countries $i=1,2,3$ each populated with a fixed number of $N_{i}$ immobile citizens. Households have a common per capita capital endowment $(e)$ and a labor endowment $(l=1)$, which they supply inelastically. Labor is immobile while capital is perfectly mobile internationally.

\section{$2.1 \quad$ Firms}

Each country produces one good using a stock of capital $\left(K_{i}\right)$ and effort from labor $\left(N_{i}\right)$. There is perfect competition in the output market. For each country, the production function $F\left(K_{i}, N_{i}\right)$ is homogeneous of degree one, so it can be written in intensive form: $N_{i} f\left(k_{i}\right)$ 
where $k_{i}=K_{i} / N_{i}$ denotes the capital-labor ratio employed in country $i . F($.$) is concave in$ its two inputs and twice continuously differentiable. Hence: $f^{\prime}\left(k_{i}\right)>0, f^{\prime \prime}\left(k_{i}\right)<0$. Profit maximizing firms set the marginal product of capital equal to its price: the tax-inclusive cost of capital. Thereby, firms face a distortionary source-based unit specific tax on capital $\left(t_{i}\right) !^{2}$ Hence, the first-order condition for profit maximization yields for all $i$ :

$$
f_{i}^{\prime}(.)=t_{i}+\rho
$$

The after-tax rate of return on capital $(\rho)$ is equal across countries due to the international mobility of capital. The wage rate per worker equals firm revenue minus capital costs: $f_{i}()-$. $f_{i}^{\prime}(.) k_{i}$

\subsection{Consumers}

A representative consumer features a twice-continuously differentiable, monotonously increasing utility function of the form: $U_{i}\left(g_{i}, c_{i}\right)$, where $g_{i}$ and $c_{i}$ denote, respectively public and private consumption. Public consumption reflects a publicly provided private good, rather than a pure public good. Household private consumption is subject to a household budget constraint, given by:

$$
c_{i}=\left[f_{i}(.)-f_{i}^{\prime}(.) k_{i}\right]+\rho e .
$$

Hence, private consumption equals the wage, reflected by the term in between square brackets on the right-hand side of Eq. (2), plus interest income from the capital endowment $(\rho e)$.

\subsection{Government}

The government maximizes welfare, which is determined by the utility of the representative household. It chooses the optimal tax rate $t_{i}$, thereby taking into account the government budget constraint that restricts public consumption to tax revenues:

\footnotetext{
${ }^{2}$ Lockwood (2004) analyses the consequences of replacing the unit-specific tax rate with an ad valorem tax rate. Results are comparable, only tax competition is more intense under ad valorem tax rates.
} 


$$
g_{i}=t_{i} k_{i} .
$$

Optimization with respect to the tax rate is equivalent to optimization with respect to the provision of public goods. The optimum satisfies the following condition:

$$
\frac{\partial U_{i} / \partial t_{i}}{U_{c}(.)}=\left[\frac{\partial c_{i}}{\partial t_{i}}\right]+M R S\left(c_{i}, g_{i}\right)\left[\frac{\partial g_{i}}{\partial t_{i}}\right]=0
$$

where $\operatorname{MRS}\left(c_{i}, g_{i}\right)=U_{g}(.) / U_{c}()>$.0 denotes the marginal rate of substitution between public and private goods. The right-hand side of Eq. (4) measures the welfare effect of the tax via, respectively, changes in private consumption and public consumption.

\subsection{Equilibrium}

Countries differ in size. To simplify the analysis, we assume: $s_{1}=s_{2}=s \neq s_{3}=(1-2 s)$, where $s_{i}=N_{i} / N$, denotes the share of the population of country $i$ in the world population $(N)$. With a fixed world capital stock of $\bar{K}=N e$, the world resource constraint reads as:

$$
\begin{aligned}
\bar{K} & =K_{1}+K_{2}+K_{3}, \\
e & =s_{1} k_{1}+s_{2} k_{2}+s_{3} k_{3} .
\end{aligned}
$$

Eq. (5) together with each country's demand for capital in Eq. (1) determine the capital stock in each country and the world rate of return, $k_{i}$ and $\rho$ respectively. Both are implicit functions of the set of tax rates $\left[t_{1}, t_{2}, t_{3}\right] !^{3}$

\section{Optimal tax rates under four regimes}

We now derive expressions for the optimal tax rates in the three countries, which are characterized by Eq. (4). To that end, we rewrite the derivatives in Eq. (4) by differentiating Eq.

\footnotetext{
${ }^{3}$ We assume that $\rho>0$, ruling out the possibility of an excess supply regime where part of the capital stock is not used (see Bucovetsky, 1991).
} 
(2) and (3) with respect to the tax rate:

$$
\begin{aligned}
\frac{\partial c_{i}}{\partial t_{i}} & =-f_{i}^{\prime \prime}(.) \frac{\partial k_{i}}{\partial t_{i}} k_{i}+\frac{\partial \rho}{\partial t_{i}} e<0, \\
\frac{\partial g_{i}}{\partial t_{i}} & =k_{i}\left[1+\frac{t_{i}}{k_{i}} \frac{\partial k_{i}}{\partial t_{i}}\right]>0 .
\end{aligned}
$$

Eq. (6) shows that a higher tax rate reduces private consumption for two reasons. First, a higher tax will cause an outflow of capital (see below). The smaller capital stock reduces labor productivity and, therefore, the wage and private consumption. Second, the higher tax reduces the world rate of return on capital and, therefore, interest income. This magnifies the reduction in private consumption.

Eq. (7) shows that the effect of a higher tax on public consumption depends on the Laffer curve. In particular, the first term on the right-hand side of Eq. (7) shows that a higher tax raises revenue over the existing tax base. The second term indicates that a higher tax causes an erosion of the tax base to the extent that it reduces the domestic capital stock. This reduces tax revenue, especially when the initial tax rate is high. As long as we are on the upward sloping part of the Laffer curve, the first term dominates and public consumption increases in the tax rate.

By differentiating Eq. (1), we find how a change in the tax rate of country $i$ affects its capital stock:

$$
\frac{\partial k_{i}}{\partial t_{i}}=\frac{1}{f_{i}^{\prime \prime}(.)}\left[1+\frac{\partial \rho}{\partial t_{i}}\right]
$$

As $f_{i}^{\prime \prime}()<$.0 , Eq. (8) suggests that a higher tax reduces capital in country $i$ as long as the term between square brackets on the right-hand side is positive. This term denotes the net effect on the cost of capital. The first term captures the direct increase in the cost of capital due to a higher tax rate. The second term shows an offsetting effect associated with a lower interest rate. In particular, the interest rate is determined on the world capital market. Lower capital demand in country $i$ may reduce the interest rate if country $i$ exerts market power on the world capital market. The adjustment in the capital stock in Eq. (8) implies that the before-tax return to capital in country $i$ changes enough to equalize after-tax rates 
of return across countries. This restores equilibrium on the international capital market. The speed at which capital adjust in country $i$ is governed by $f_{i}^{\prime \prime}($.$) .$

We define $\epsilon_{K, i} \equiv-\frac{t_{i}}{k_{i}} \frac{\partial k_{i}}{\partial t_{i}} \geq 0$ as minus the tax elasticity of capital and $\epsilon_{R, i} \equiv-\frac{\partial \rho}{\partial t_{i}} \geq 0$ as minus the tax-rate elasticity of the interest rate. Together with Eq. (6), (7) and (8), we can rewrite (Eq. 4) as:

$$
M R S_{i}(.)=M C F_{i}=\frac{1+\epsilon_{R, i}\left[\left(e / k_{i}\right)-1\right]}{1-\epsilon_{K, i}},
$$

Eq. (9) reflects the modified Samuelson rule for publicly provided private goods. It shows that the marginal rate of substitution between public and private goods on the left-hand side is equal to the marginal cost of public funds (henceforth $M C F$ ) times the marginal rate of transformation (which equals unity in our model). Eq. (9) shows that the $M C F_{i}$ rises in the tax elasticity of capital $\epsilon_{K, i}$. Intuitively, a higher elasticity implies a larger erosion of the tax base. Accordingly, the tax is more distortionary. The $M C F_{i}$ in Eq. (9) increases also in $\epsilon_{R, i}$ if country $i$ is a net capital exporter $\left(e>k_{i}\right)$. It decreases if it is a net capital importer $\left(e<k_{i}\right)$. Intuitively, a net capital exporter is a net receiver of interest vis a vis the rest of the world. Therefore, it suffers from a welfare loss if the interest rate drops. This makes public goods more expensive as higher taxes reduce the interest rate. For a net capital importer, the lower interest rate is a net benefit because the country would pay less to foreign capital owners. This reduces the $M C F$.

The elasticities $\epsilon_{K, i}$ and $\epsilon_{R, i}$ in Eq. (9) vary with the tax regime adopted by countries. Appendix A derives expressions for these elasticities under four different regimes: full harmonization, decentralization, ECA under Nash and ECA under Stackelberg behavior of governments. Table 1 summarizes the elasticities under these four regimes. Note, however, that the elasticities in Table 1 cannot be directly compared as they are evaluated at different equilibria (i.e. at different levels of $k_{i}$ and $t_{i}$ ). Yet, we can compare their values when evaluated at one equilibrium, e.g. the decentralized equilibrium.

\footnotetext{
${ }^{4}$ We assume that both $g_{i}$ and $c_{i}$ are normal goods. It follows that: $\partial M R S_{i}(.) / \partial t_{i}<0$, i.e. choosing a higher tax rate leads to a reduction in the marginal valuation of the public good. The assumption of normal goods implies: $\partial M R S_{i}(.) / \partial c_{i}>0$ and $\partial M R S_{i}(.) / \partial g_{i}<0$. This assumption is used by Bayindir-Upmann and Ziad (2005) to proof the existence of a second-order locally consistent equilibrium for classical tax competition models.
} 
Table 1: Elasticites under four different regimes

Regime

$\begin{array}{lll}\text { Harmonisation }(H) & \epsilon_{K, i}^{H}=0 & \epsilon_{R, i}^{H}=1 \\ \text { Decentralisation }(D) & \epsilon_{K, i}^{D}=-\frac{t_{i}}{f_{i}^{\prime \prime}(.) k_{i}}\left[\frac{s_{j}\left(1 / f_{j}^{\prime \prime}(.)\right)+s_{k}\left(1 / f_{k}^{\prime \prime}(.)\right)}{\Delta}\right]>0 & \epsilon_{R, i}^{D}=\frac{s_{i}\left(1 / f_{i}^{\prime \prime}(.)\right)}{\Delta}>0 \\ & & \\ \text { ECA Nash }(N) & \epsilon_{K, u}^{N}=-\frac{t_{u}}{f_{u}^{\prime \prime}(.) k_{u}}\left[\frac{(1-2 s)\left(1 / f_{3}^{\prime \prime}(.)\right)}{\Delta}\right]>0 & \epsilon_{R, u}^{N}=\frac{2 s\left(1 / f_{u}^{\prime \prime}(.)\right)}{\Delta}>0 \\ & \epsilon_{K, 3}^{N}=-\frac{t_{3}}{f_{3}^{\prime \prime}(.) k_{3}}\left[\frac{2 s\left(1 / f_{u}^{\prime \prime}(.)\right)}{\Delta}\right]>0 & \epsilon_{R, 3}^{N}=\frac{(1-2 s)\left(1 / f_{3}^{\prime \prime}(.)\right)}{\Delta}>0 \\ \text { ECA Stackelberg }(S) & \epsilon_{K, u}^{S}=\epsilon_{K, u}^{N}-\epsilon_{K, 3}^{N} E\left[\partial t_{3} / \partial t_{u}\right] & \epsilon_{R, u}^{S}=\epsilon_{R, u}^{N}+\epsilon_{R, 3}^{N} E\left[\partial t_{3} / \partial t_{u}\right] \\ & \left.\epsilon_{K, 3}^{S}=\epsilon_{K, 3}^{N}\right] & \epsilon_{R, 3}^{S}=\epsilon_{R, 3}^{N} \\ \text { Common denominator } & \Delta=s_{1}\left(1 / f_{1}^{\prime \prime}(.)+s_{2}\left(1 / f_{2}^{\prime \prime}(.)\right)+s_{3}\left(1 / f_{3}^{\prime \prime}(.)\right)<0\right.\end{array}$

\subsection{Harmonization}

We use superscript " $\mathrm{H}$ " to indicate variables udner the harmonized regime. If countries harmonize their tax systems, they adopt uniform tax rates and simultaneously modify them. According to Table 1, this implies that $\epsilon_{K, i}^{H}=0$ and $\epsilon_{R, i}^{H}=1$. Intuitively, Eq. 5 shows that the world capital stock is fixed and supplied inelastically. Hence, a global tax on capital comes down to a lump-sum tax. As capital does not change, any tax should be absorbed by a change in the interest rate. The uniform global tax rate is equal in all countries, so that $k_{i}=e$. As a result, Eq. (6) and 77 simplify to $\frac{\partial c_{i}(.)}{\partial t_{i}}=-k_{i}$ and $\frac{\partial g_{i}(.)}{\partial t_{i}}=k_{i}$, i.e. a higher tax on capital transfers funds from private to public consumption, without inducing distortions. The $M C F_{i}$ in Eq. (9) equals unity and the marginal rate of substitution between public and private goods equals its marginal rate of transformation. This reflects the ordinary Samuelson rule for the optimal provision of public goods. Global harmonization thus brings us in a first-best world.

\subsection{Decentralization}

Under decentralization, countries set their tax rates individually. We assume that governments do not take into account the impact of their own tax rate on other countries' policies, i.e. we derive the Cournot-Nash equilibrium. Superscript "D" denotes variables evaluated 
under the decentralized regime. The elasticity $\epsilon_{K, i}^{D}$ in Table 1 is unambiguously positive, i.e. an increase in $t_{i}$ reduces capital in country $i$. The elasticity depends on the capital demand responses in other countries, which determine the impact on the world interest rate. Note that governments will never set tax rates on the downward sloping part of the Laffer curve, implying: $0<\epsilon_{K, i}^{D}<1$. In Table 1 , we see that $0<\epsilon_{R, i}^{D}<1$. Hence, a higher tax rate in country $i$ unambiguously reduces the world interest rate.

The $M C F_{i}$ under decentralization in Eq. (9), denoted by $M C F_{i}^{D}$, exceeds unity for capital exporting countries (where $e / k_{i}>1$ ). For these countries, both the distortion in capital demand and the reduction in the interest rate render the tax distortionary. In capital importing countries (where $\left.e / k_{i}<1\right), M C F_{i}^{D}$ exceeds unity only if the decline in capital induced by taxes, as measured by $\epsilon_{K, i}^{D}$, is large relative to the benefit of a lower interest rate, as measured by $\epsilon_{R, i}^{D}\left[\left(e / k_{i}\right)-1\right]$. Intuitively, capital importers export part of the tax burden abroad to foreign capital owners by reducing the interest rate.

\subsection{ECA Nash}

Under the enhanced cooperation agreement (ECA), countries 1 and 2 form a union $(u)$ in setting their tax rates. Country 3 does not join this union. As countries 1 and 2 are equivalent, we have: $k_{u}=k_{1}=k_{2}, f_{u}^{\prime \prime}()=.f_{1}^{\prime \prime}()=.f_{2}^{\prime \prime}($.$) and t_{u}=t_{1}=t_{2}$. We assume that the ECA countries maximize the sum of welfare in the two countries: $s U_{1}()+.s U_{2}()=.2 s U_{u}($.$) and U_{u}$ denotes per capita welfare in the ECA. With respect to expectations of ECA governments, we start with the Cournot-Nash assumption that was also adopted under decentralization. That is, we assume that both the ECA countries and country 3 take the tax policy of the other country as given when deciding on their own tax policy. We use superscript " $N$ " to indicate the case of Enhanced Cooperation under Cournot-Nash.

Table 1 shows that the elasticities for country 3 are the same. Neither its size nor the number of jurisdictions it competes with has changed. Hence, the creation of the ECA does not directly influence $M C F_{3}^{N}$. For countries 1 and 2 , Table 1 shows that the elasticities differ from those under decentralization (when evaluated at the same equilibrium). In particular, $\epsilon_{K, 1}^{D}=\epsilon_{K, 2}^{D}>\epsilon_{K, u}^{N}$, i.e. ECA countries feature a smaller tax elasticity of capital than under 
decentralization. Intuitively, the ECA eliminates capital flows across the two ECA countries, which makes capital less responsive to the tax. Effectively, the ECA countries have grown bigger, which reduces their tax elasticity of capital. Table 1 shows further that $\epsilon_{R, u}^{N}>\epsilon_{R, 1}^{D}=$ $\epsilon_{R, 2}^{D}$. The interest rate response to the tax is twice as large because ECA countries together are twice the size of a single country.

These results imply that, at the decentralized equilibrium, the $M C F_{u}^{N}$ is smaller than $M C F_{i}^{D}$ for $i=1,2$ on account of the smaller elasticity of capital demand. The larger taxrate elasticity of the interest rate further reduces the $M C F_{u}^{N}$ if the ECA countries are net capital importers. However, a larger interest elasticity mitigates the reduction in the $M C F_{u}^{N}$ when ECA countries are net capital exporters.

\subsection{ECA Stackelberg}

Under Stackelberg, one country foresees the strategic tax reaction by the other country when deciding about its own tax policy. This is the Stackelberg leader. In our analysis, we consider the case where the ECA countries act as Stackelberg leader. Hence, the ECA countries choose their optimal point on the reaction function of country 3 . We use superscript "S" to indicate the case of Enhanced Cooperation under Stackelberg.

The elasticities under Stackelberg, $\epsilon_{R, i}^{S}$ and $\epsilon_{K, i}^{S}$ in Table 1, depend on the strategic reaction of country $3\left(\partial t_{3} / \partial t_{u}\right) !^{5}$ We compare these elasticities with those under decentralization and ECA Nash, again evaluated at the decentralized equilibrium. If taxes are strategic complements (i.e. if $\partial t_{3} / \partial t_{u}>0$ ), we see from Table 1 that the tax elasticity of capital in the ECA countries will be smaller than under Nash, i.e. $\epsilon_{K, u}^{S}<\epsilon_{K, u}^{N}$. The reason is that the ECA countries realize that country 3 will set a higher tax rate in response to the higher rate in the ECA countries, which mitigates the expected capital outflow. However, if taxes are strategic substitutes (i.e. if $\partial t_{3} / \partial t_{u}<0$ ), we have $\epsilon_{K, u}^{S}>\epsilon_{K, u}^{N}$. The expected erosion of the tax base is now larger under Stackelberg than under Nash, because country 3 reduces its tax in response

\footnotetext{
${ }^{5}$ If country 3 would aggessively respond in the opposite direction to tax changes in the ECA, it is possible that the sign of the elasticities changes. We rule out this possibility, however, and will assume that $\epsilon_{R, i}^{S}>0$ and $\epsilon_{K, i}^{S}>0$.
} 
to the higher rate in the ECA countries. This reinforces the outflow of capital. In this case, we cannot be sure that $\epsilon_{K, u}^{S}$ is smaller than $\epsilon_{K, 1}^{D}=\epsilon_{K, 2}^{D}$.

Under strategic complementarity, the higher tax rate in ECA countries amplifies the reduction in the interest rate compared to the ECA-Nash regime, i.e. $\epsilon_{R, u}^{S}>\epsilon_{R, u}^{N}$. For capital importing countries, both the smaller capital elasticity and a larger interest elasticity reduce the $M C F$ under Stackelberg compared to Nash. For a capital exporter, strategic complementarity implies offsetting effects on the $M C F$ as the higher interest elasticity raises the $M C F$. Under strategic substitutability, we have $\epsilon_{R, i}^{S}<\epsilon_{R, i}^{N}$. In that case, the $M C F$ is unambiguously larger under Stackelberg than under Nash for capital importing countries (for whom both the capital elasticity is larger and the interest elasticity is smaller). For capital exporting countries, the two effects are offsetting. We cannot draw conclusions how the Stackelberg outcome compares to the decentralized equilibrium.

\subsection{The impact of country size}

The formation of an ECA has the same properties as an increase in country size of the cooperating countries. Indeed, country size determines the elasticities $\epsilon_{K, i}$ and $\epsilon_{R, i}$ and, therefore, the optimal tax rates. For instance, the partial derivatives of $\epsilon_{K, 1}$ and $\epsilon_{R, 1}$ with respect to the size of country 1 are given by:

$$
\begin{aligned}
& \frac{\partial \epsilon_{K, 1}^{D}}{\partial s_{1}}=-\epsilon_{K, 1}^{D} \frac{1 / f_{1}^{\prime \prime}}{\Delta}<0, \\
& \frac{\partial \epsilon_{R, 1}^{D}}{\partial s_{1}}=\epsilon_{R, 1}^{D}\left[1-\epsilon_{R, 1}^{D}\right]>0 .
\end{aligned}
$$

Eq. (10) and (11) suggest that country size reduces the tax elasticity of capital and increases the tax-rate elasticity of the interest rate. The lower interest elasticity is because large countries have more market power on the world capital market. In turn, this implies a bigger offsetting impact of the tax on the cost of capital, causing a smaller tax elasticity of capital. On account of the smaller $\epsilon_{K, i}$, large countries feature a lower $M C F$ and will set a higher tax rate than small countries. For that reason, large countries will be capital exporters and small countries will be capital importers. 


\section{Strategic tax responses}

The strategic tax response by country $3, \partial t_{3} / \partial t_{u}$, plays a crucial role under Stackelberg. As we will see shortly, these strategic tax responses are also vital for the equilibrium outcomes under Nash as well as the welfare implications of an ECA. To understand the factors determining strategic tax responses, this section derives them analytically. In general, tax reaction functions take the form: $t_{i}=F_{i}\left(t_{j}, t_{k}\right)$, where $F_{i}\left(t_{j}, t_{k}\right)$ gives the best response of country $i$ to the tax rates chosen by countries $j$ and $k$. Unfortunately, we are unable to find closed form expressions for the tax rates under each regime. Therefore, we linearize the tax reaction around an initial equilibrium. This yields analytical expressions of the tax by a country in response to tax changes in the other countries. The linearized tax responses reflect marginal tax changes, relative to the initial equilibrium.

\subsection{Linearization}

A change in tax policy by neighboring countries will change both the $M R S$ on the left-hand side of Eq. (9) and the $M C F$ on the right-hand side. To obtain a reduced form expression for the tax reaction function, we linearize both:

$$
\widetilde{M R S}_{i}={\widetilde{M C F_{i}}}_{\text {, }}
$$

where a tilde $(\sim)$ denotes a relative change.

First, we linearize the $M C F$ on the right-hand side of Eq. (12). From Eq. (9) we know that the $M C F$ depends on $\epsilon_{K, i}, \epsilon_{R, i}$ and $k_{i}$. Hence, we can write the linearized $M C F$ as:

$$
\widetilde{M C F_{i}}=\eta_{i} \widetilde{\epsilon_{K, i}}+\lambda_{i} \widetilde{\epsilon_{R, i}}-\mu_{i} \tilde{k}_{i}
$$

where

$$
\eta_{i} \equiv \frac{\epsilon_{K, i}}{1-\epsilon_{K, i}}>0, \quad \lambda_{i} \equiv \frac{\epsilon_{R, i}\left[e / k_{i}-1\right]}{1+\epsilon_{R, i}\left[e / k_{i}-1\right]}, \quad \mu_{i} \equiv \frac{\epsilon_{R, i} e / k_{i}}{1+\epsilon_{R, i}\left[e / k_{i}-1\right]}>0
$$


The $M C F$ in Eq. (13) reflects the price of the public good. The first term on the righthand side of Eq. (13) shows by how much the $M C F$ rises in the tax elasticity of capital. This effect, captured by $\eta_{i}$, is non-linear in the elasticity. In particular, the closer a country is to the top of the Laffer curve $\left(\epsilon_{K, i} \approx 1\right)$, the larger is the impact of a marginal change in the elasticity on the $M C F$.

The second term on the right-hand side of Eq. (13) cannot be signed unambiguously as it depends on the status of a country regarding capital export. If a country is a net capital importer $\left(e / k_{i}<1\right)$, we see that $\lambda_{i}<0$, i.e. a higher interest elasticity reduces the $M C F$. This is because a capital importer can shift part of its tax burden unto foreign suppliers of capital. For a capital exporting country, however, $\lambda_{i}>0$ so that a higher interest elasticity raises the $M C F$.

The third term on the right-hand side of Eq. 13 suggests that a higher capital stock will ceteris paribus reduce the $M C F$. The reason is that an increase in the capital stock (for a given endowment of capital owned by domestic residents, e) will make reductions in the interest rate less costly at the margin. Indeed, more interest needs to be paid to foreign capital owners so that the potential for tax exportation increases. Accordingly, taxes become less costly because they reduce the interest rate through $\epsilon_{R, i}$.

Second, we linearize the $M R S$ on the left-hand side of Eq. (12) for a CES utility function:

$$
\widetilde{M R S} S_{i}=\frac{\widetilde{c}_{i}-\widetilde{g}_{i}}{\sigma_{g c}}
$$

where $\sigma_{g c} \equiv \operatorname{dlog}\left(c_{i} / g_{i}\right) / \operatorname{dlog}\left(M R S_{i}\right)>0$ denotes the elasticity of substitution between public and private goods which describes the slope of the indifference curve between public and private consumption. $\sigma_{g c}$ therefore determines the change in the willingness to pay for public goods following a change in the ratio of private to public consumption. If $\sigma_{g c}$ is large, public and private goods are close substitutes, such that the willingness to pay for public goods is not strongly affected by changes in the ratio of private to public consumption.

We substitute Eq. (1) into the household budget constraint Eq. (2) to eliminate $f_{i}^{\prime}$ and get for private consumption: $c_{i}=f_{i}()+.\rho\left(e-k_{i}\right)-t_{i} k_{i}$. Linearizing this expression and 
combining it with the government budget constraint in Eq. (3), we arrive at an expression for the ratio of private and public consumption:

$$
\tilde{c}_{i}-\tilde{g}_{i}=-\tilde{k}_{i}+\phi_{i} \tilde{\rho}-\frac{1}{\alpha_{i}} \tilde{t}_{i}
$$

where $\alpha_{i} \equiv c_{i} /\left(c_{i}+g_{i}\right)$ and $\left.\phi_{i} \equiv\left(e-k_{i}\right) \rho / c_{i}\right)$. The first term on the right-hand side of Eq. (15) states that a higher capital stock directly reduces the ratio of private-to-publicconsumption. The reason is that, at the margin, an inflow of capital leaves private consumption unchanged as returns to capital are transferred abroad. However, public revenue increases due to a broader capital tax base. Hence, an inflow of capital directly reduces the ratio of private to public consumption.

The second term on the right-hand side of Eq. (15) measures the impact of a higher interest rate. On the one hand, a higher interest rate directly increases income from the capital endowment received by the residents of country $i$, which raises private consumption. On the other hand, a higher interest rate increases the capital costs for firms. This reduces wages and, therefore, private consumption. On balance, the net impact of a higher interest rate depends on the coefficient $\phi_{i}$, which depends on net capital exports. For a net capital exporter, we have $\phi_{i}>0$ so that the positive effect on interest income dominates the negative wage effect. Hence, a higher interest rate increases private consumption. For a net capital importer, we have $\phi_{i}<0$ so that a higher interest rate reduces private consumption.

The third term on the right-hand side of Eq. (15) captures the direct negative impact of a higher tax on the ratio of private to public consumption. This effect depends on the initial share of private consumption, $\alpha_{i}$.

If we substitute Eq. (13) and Eq. (15) into Eq. (14), we arrive at an expression for the change in the tax rate of country $i$, as a function of the changes in the capital stock, the interest rate and the elasticities:

$$
\frac{1}{\alpha_{i}} \tilde{t}_{i}=\left[\mu_{i}-\frac{1}{\sigma_{g c}}\right] \tilde{k}_{i}+\frac{\phi_{i}}{\sigma_{g c}} \tilde{\rho}-\eta_{i} \widetilde{\epsilon_{K, i}}-\lambda_{i} \widetilde{\epsilon_{R, i}}
$$




\subsection{Starting from the decentralized equilibrium}

We will now rewrite the variables on the right-hand side of Eq. (16) in terms of changes in tax rates. Thereby, we start from the initial decentralized equilibrium. One interpretation is that countries 1 and 2 have just formed an ECA, but have not yet modified their policies. Hence, they consider a marginal change in their tax rates, starting from the initial decentralized equilibrium. Our focus will be entirely on the strategic tax responses. Hence, we do not show the direct change in the tax rate of countries 1 and 2 due to the formation of the ECA in our linearization. Instead, our focus is entirely on the strategic tax responses ${ }^{6}$

To arrive at the relative change in the elasticities on the right-hand side of Eq. (16), we need to specify a production function. With a general production function, we obtain complex expressions for the elasticities and ambiguous signs for the impact of capital inflows on the elasticity:7 We follow Bucovetski (1991) and Wilson (1991) by adopting a quadratic production function of the form: $f(k)=(a-1 / 2 b k) k$. This allows us to obtain more simple analytical reduced form equations for the elasticities. In particular, the quadratic form implies for the elasticities: $\epsilon_{K, i}=\frac{t_{i}\left(1-s_{i}\right)}{b k_{i}}$ and $\epsilon_{R, i}=s_{i}$. By linearization, we obtain:

$$
\widetilde{\epsilon_{K, i}}=\tilde{t}_{i}-\widetilde{k}_{i} \text { and } \widetilde{\epsilon_{R, i}}=0
$$

Hence, the tax elasticity of the capital stock rises proportionally in the tax rate and in reductions in the capital stock, which is due to the broadening of the tax base. The interest elasticity is not marginally affected by the tax rate.

To rewrite the relative changes in the interest rate and the capital stock on the right-hand side of Eq. (16), we linearize the capital market equilibrium in Eq. (5) and the first-order

\footnotetext{
${ }^{6}$ One could include a change in the value of the elasticities induced by the shock of the ECA formation. At the margin, it yields similar effects as a change in the size of the ECA countries.

${ }^{7}$ The linearized elasticities for a general production function take the form: $\widetilde{\epsilon_{K, i}}=\widetilde{t_{i}}-\left(1+\pi_{1, i} \nu_{1, i}-\pi_{2, i}\right) \widetilde{k_{i}}$ and $\widetilde{\epsilon_{R, i}}=\nu_{1, i} \widetilde{k_{i}}$, where the parameters $\pi_{1, i}, \pi_{2, i}$ and $\nu_{1, i}$ are positive. For a sufficiently large country: $1+\pi_{1, i} \nu_{1, i}>\pi_{2, i}$ and the tax elasticity of capital is decreasing in the capital stock. For smaller countries, the tax elasticity of capital is increasing in the capital stock. Derivations can be obtained upon request at the authors.
} 
condition for firms in Eq. (1). This yields:

$$
\begin{aligned}
\tilde{\rho} & =-\frac{t_{i}}{\rho} \epsilon_{R, i} \tilde{t}_{i}-\frac{t_{j}}{\rho} \epsilon_{R, j} \tilde{t}_{j}, \\
\tilde{k}_{i} & =-\epsilon_{K, i} \tilde{t}_{i}+\epsilon_{K, j i} \tilde{t}_{j},
\end{aligned}
$$

for $i \neq j=u, 3$, where $\epsilon_{K, j i} \equiv-\frac{t_{j}}{f_{i}^{\prime \prime} k_{i}} \frac{s_{j}\left(1 / f_{j}^{\prime \prime}\right)}{\Delta}>0$ denotes the cross-tax elasticity of capital demand in country $i$ with respect to the tax rate in country $j$. Eq. 18 shows that taxes in both ECA and non-ECA countries reduce interest rates, with an impact size determined by the interest elasticity. The first term in Eq. (19) shows that capital declines in the own tax rate of a country, an effect measured by the tax elasticity of capital. The second term in Eq. (19) shows by how much capital demand in country $i$ increases if country $j$ increases its tax, an effect that is always positive.

Substituting Eq. (17), (18) and (19) into Eq. (16), we find the linearized tax reaction function:

$$
\begin{gathered}
\nabla_{i} \tilde{t}_{i}=\left[\left(\mu_{i}+\eta_{i}\right) \epsilon_{K, j i}-\frac{\epsilon_{K, j i}}{\sigma_{g c}}-\frac{\phi_{i}}{\sigma_{g c}} \frac{t_{j}}{\rho} \epsilon_{R, j}\right] \tilde{t}_{j} \text { for } i \neq j=u, 3, \\
\nabla_{i} \equiv \frac{1}{\sigma_{g c} \alpha_{i}}+\eta_{i}+\left(\left(\mu_{i}+\eta_{i}\right)-\frac{1}{\sigma_{g c}}\right) \epsilon_{K, i}+\frac{\phi_{i}}{\sigma_{g c}} \frac{t_{i}}{\rho} \epsilon_{R, i}>0 .
\end{gathered}
$$

The right-hand side of Eq. 20 determines the strategic tax change of country $i$ in response to an increase in the tax rate of country $j$. The coefficient between square brackets determines whether taxes are strategic substitutes or strategic complements. For instance, the tax rate of country 3 is a strategic complement to the tax rate in the ECA countries if the following condition holds:

$$
\overbrace{\left(\mu_{3}+\eta_{3}\right) \epsilon_{K, 3 u}}^{\widetilde{M C F}}-\overbrace{\frac{\epsilon_{K, 3 u}}{\sigma_{g c}}-\frac{\phi_{3}}{\sigma_{g c}} \frac{t_{u}}{\rho} \epsilon_{R, u}}^{\widetilde{M R S}}>0 .
$$

Condition (21) depends on three terms. The first term, captured by $\left(\mu_{3}+\eta_{3}\right)$, measures how the flow of capital from the ECA countries to country 3 makes it attractive for the latter 
country to increase its tax due to a lower $M C F$. On the one hand, the $M C F$ falls because the inflow of capital reduces the capital elasticity (see Eq. (17)). This effect is captured by $\eta_{3}>0$. On the other hand, capital inflows make it beneficial for country 3 to export the tax burden via reductions in the interest rate. This effect is captured by $\mu_{3}>0$.

The second term in condition (21) is opposite from the first and reduces the likelihood of strategic complementarity. This term shows how the inflow of capital from the ECA countries broadens the capital tax base in country 3. This increases public revenue, thereby reducing the marginal willingness to pay for public goods. The reduction in the marginal willingness to pay for public goods depends on $\sigma_{g c}$, when public and private goods are closer substitutes (larger value of $\sigma_{g c}$ ) the reduction in the marginal willingness to pay for public goods will be smaller. The reduction in the marginal willingness to pay for public goods mitigates the tendency for country 3 to increase its tax rate.

The last term in condition (21) measures the negative impact of the higher tax in the ECA countries on the world interest rate. The lower interest rate either increases or decreases private consumption in country 3 , depending on whether it is a net capital importer $\left(\phi_{3}<0\right)$ or a net capital exporter $\left(\phi_{3}>0\right)$. If country 3 is a net capital importer (i.e. if it is a relatively small country), a lower interest rate increases private consumption because the increase in wages exceeds the reduction in interest income. In that case, the marginal willingness to pay for the public good increases. This makes it attractive for country 3 to increase its tax so that it is more likely that taxes are strategic complements. If country 3 is a net capital exporter (i.e. a relatively large country), however, they are more likely to be strategic substitutes. Again, changes in the marginal willingnes to pay for public goods depend on the size of $\sigma_{g c}$. From Eq. 211 the following proposition can be derived:

Proposition 1 The probability that country $i$ will decrease its tax rate in response to an increase in the tax rate of country $j$ (strategic substitutes) is larger when either: (i) the substitution elasticity between public and private goods $\left(\sigma_{G C}\right)$ is small, or; (ii) $\mu_{i}$ and $\eta_{i}$ are relatively small, or; (iii) country $i$ is a net capital exporter (i.e. relatively large). 
Figure 1: Tax Reaction Function Country $3, \sigma_{G C}=0.1$

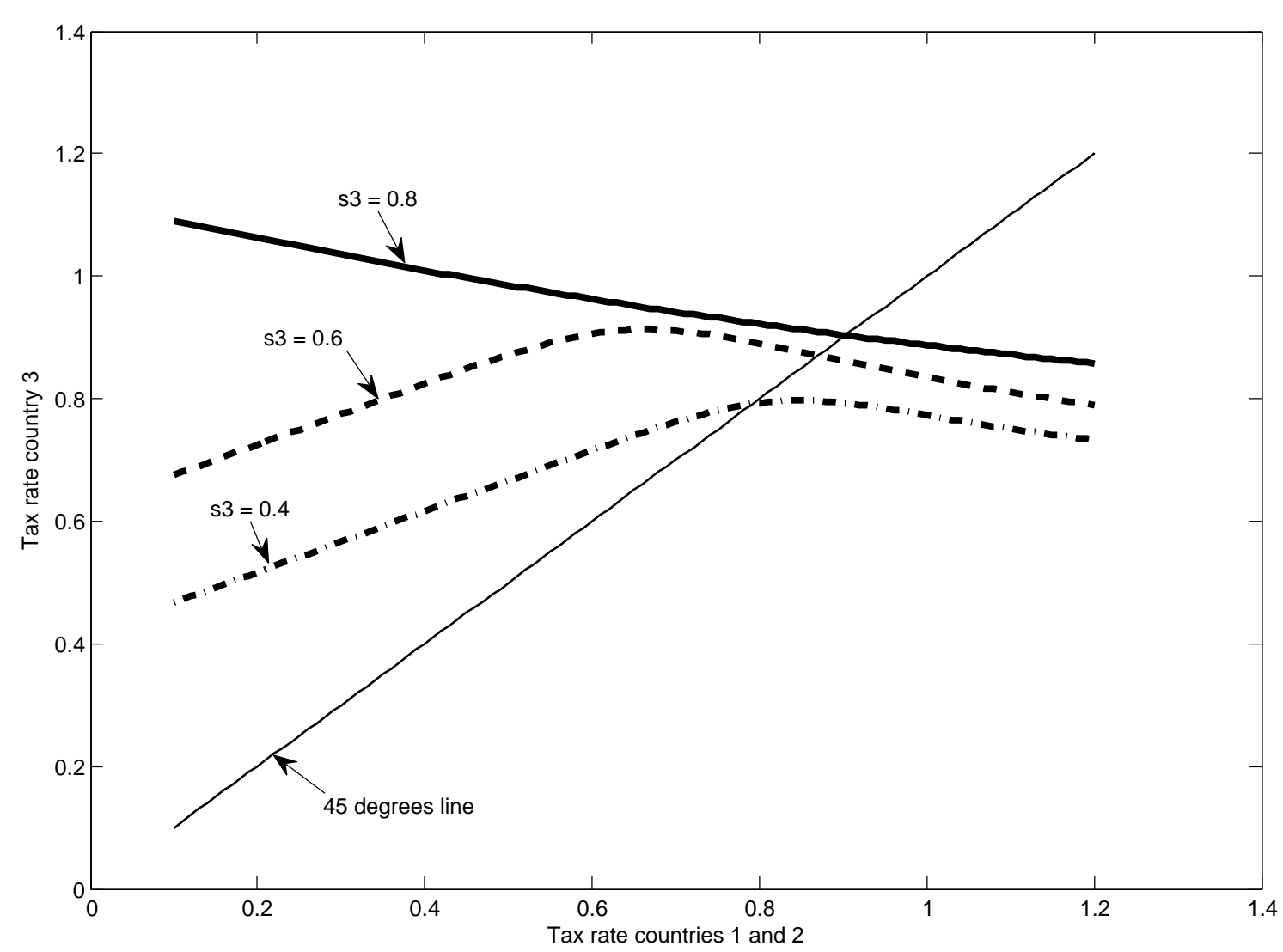

\subsection{Simulations}

Linearization offers insight in the parameters that determine the slope of the tax reaction function locally, starting from an initial equilibrium. It offers little insight, however, in the global properties of the tax reaction functions. To analyze these global properties, this subsection simulates tax reaction curves for country 3 , i.e. the outside country. In performing the simulations, we use a CES utility function of the form: $U=\left[\omega c^{(\sigma-1) / \sigma}+(1-\omega) g^{(\sigma-1) / \sigma}\right]^{(\sigma /(\sigma-1)}$ and a quadratic production function: $f(k)=(a-1 / 2 b k) k$. The parameters adopted are $\omega=1 / 4, a=2$, and $b=1 / 2$. Given the importance of the substitution elasticity between public and private goods, we consider two values: $\sigma_{g c}=0.1$ and $\sigma_{g c}=1$. We draw the fiscal reaction curves of country 3 under three different assumptions regarding its size: $s_{3}=0.8, s_{3}=0.6$ and $s_{3}=0.4$. 
Figure 2: Tax Reaction Function Country $3, \sigma_{G C}=1$

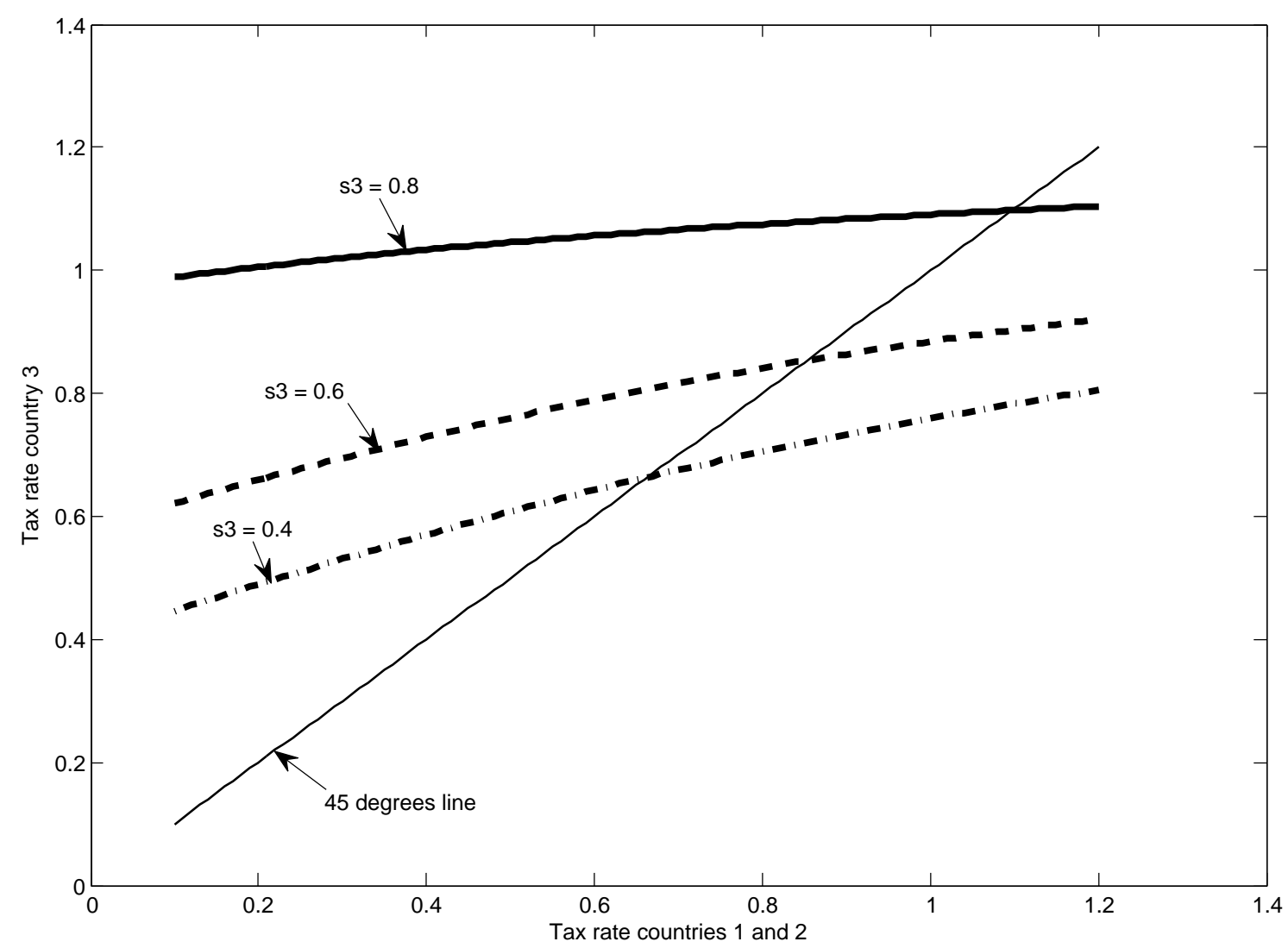

Figures (1) and (2) show the tax reaction curves for, respectively, $\sigma_{g c}=0.1$ and $\sigma_{g c}=1$. The figures suggest that the tax reaction function of country 3 shifts upwards in the size of country 3. Hence, larger countries set higher tax rates.

The slope of the fiscal reaction function is always positive in Figure (2), i.e. when $\sigma_{g c}=1$. Hence, country 3 will raise its tax in response to a higher rate in the ECA countries. This is consistent with condition 221 for strategic complementarity. Indeed, for a high value of $\sigma_{g c}$, the first term in condition (21) is relatively important, which makes strategic complementarity more likely. In Figure (1), i.e. when $\sigma_{g c}=0.1$, the tax reaction function of country 3 can be either upward or downward sloping. With a small $\sigma_{g c}$, the first term in condition (21) is relatively unimportant. Hence, the decrease in the willingness to pay for public goods dominates the tax response. by country 3 . 
If country 3 is smaller, its reaction function is steeper in Figures (1) and (2). This has two reasons. First, small countries feature a high tax elasticity of capital, which yields a high value of $\eta_{i}$. Accordingly, an inflow of capital in country 3 due to a higher tax in the ECA exerts a relatively large decline in the $M C F$. Second, small countries are net capital importers. They benefit from a lower interest rate and are more likely to increase their tax rate in response to it (see the third term in condition (21)). In Figure (1) the negative slope of the reaction curve is indeed more likely if country 3 is large.

\section{$5 \quad$ Simulating equilibrium tax rates}

This section numerically simulates the equilibrium tax rates. We do this for four different regimes (harmonization, decentralization, ECA Nash and ECA Stackelberg) and a continuum of country size configurations. Figures (3) and (4) show the equilibrium tax rates for, respectively, $\sigma_{g c}=0.1$ and $\sigma_{g c}=1$. On the horizontal axis is the size $(s)$ of countries 1 and 2 . It increases from $s=0.05$ on the left to $s=0.45$ on the right. As $s_{3}=(1-2 s)$, the size of country 3 moves between 0.9 and 0.1 . The vertical axis captures the Equilibrium tax rates. The fat lines describe the equilibrium taxes for countries 1 and 2 while the slimmer lines describe the equilibrium taxes for country 3. In performing the simulations, we use the same specifications and parameter values as in the previous section. The first-best harmonized rate, $t_{i}^{H}$, is flat in both figures and set at, respectively, $t_{i}^{H}=0.92$ and $t_{i}^{H}=1.31$ (note that these are unit specific tax rates). They serve as a benchmark for the tax rates in the other regimes.

\subsection{Decentralization}

In Figures (3) and (4), solid lines represent the equilibrium tax rates under decentralization: $t_{i}^{D}$. Under decentralization we see that governments generally set their tax rates lower than under harmonization, i.e. $t_{i}^{D}<t_{i}^{H}$. For instance, if countries are symmetric $(s=0.33)$, the optimal decentralized tax in all countries is $t_{i}^{D}=0.74$ when $\sigma_{g c}=0.1$ and $t_{i}^{D}=0.61$ when $\sigma_{g c}=1$. This reflects the fiscal externality associated with tax competition: the tax induces an outflow of capital to other countries, which hurts domestic welfare. Accordingly, countries 
set lower tax rates as they do not take into account the benefits from the outflow of capital for other countries. This fiscal externality is responsible for an underprovision of public goods (Zodrow and Mieskowski, 1986).

However, tax rates are not always lower under decentralization compared to harmonization. Indeed, Figure (3) shows the tax rates for $\sigma_{g c}=0.1$. If $s_{3}$ is sufficiently large, we see that this country will set its tax rate under decentralization above the harmonized rate $\left(t_{3}^{D}>t_{3}^{H}\right)$. The reason is that the small countries 1 and 2 set a much lower tax rate under decentralization than under harmonization. This causes an outflow of capital from country 3 to countries 1 and 2. Compared to the harmonized regime, country 3 thus has a smaller tax base and supplies fewer public goods for the same level of tax as under harmonization. If substitution between public and private consumption is difficult, the lower level of public goods is relatively costly in terms of welfare. Accordingly, the government of country 3 finds it optimal to increase the tax to raise the level of public goods. This raises the tax rate above the level under harmonization. Note that the level of public consumption might still be lower under decentralization due to the outflow of capital from country 3 to countries 1 and 2. Figure (4) shows that the upward effect on the tax in country 3 is not sufficiently strong to compensate for the fiscal externality if $\sigma_{g c}=1$. In that case, decentralized tax rates are always lower than the harmonized rate.

In Figure (3), tax rates always increase in size. This is consistent with the partial derivatives of the elasticities with respect to size in Eq. (10) and Eq. (11). Intuitively, a larger country features a lower tax elasticity of capital, $\epsilon_{K, i}$ and a higher tax rate elasticity of the interest rate, $\epsilon_{R, i}$. This is generally associated with a lower $M C F$ and a higher tax. Also in Figure (4), the tax rate in country 3 increases in size. However, this is not the case for countries 1 and 2. Indeed, the relationship between the size of the ECA countries and the tax rate is U-shaped. Hence, for very small size, countries 1 and 2 set a higher tax rate than when they are slightly larger. For instance, Figure (4) shows that the tax in countries 1 and 2 is larger when $s=0.05$ than when $s=0.2$. This is due to general equilibrium effects induced by strategic tax responses. In particular, if the size of countries 1 and 2 is marginally increased, the size of country 3 is marginally decreased. From a partial equilibrium argument, countries 
Figure 3: Equilibrium tax rates under four regimes, $\sigma_{G C}=0.1$

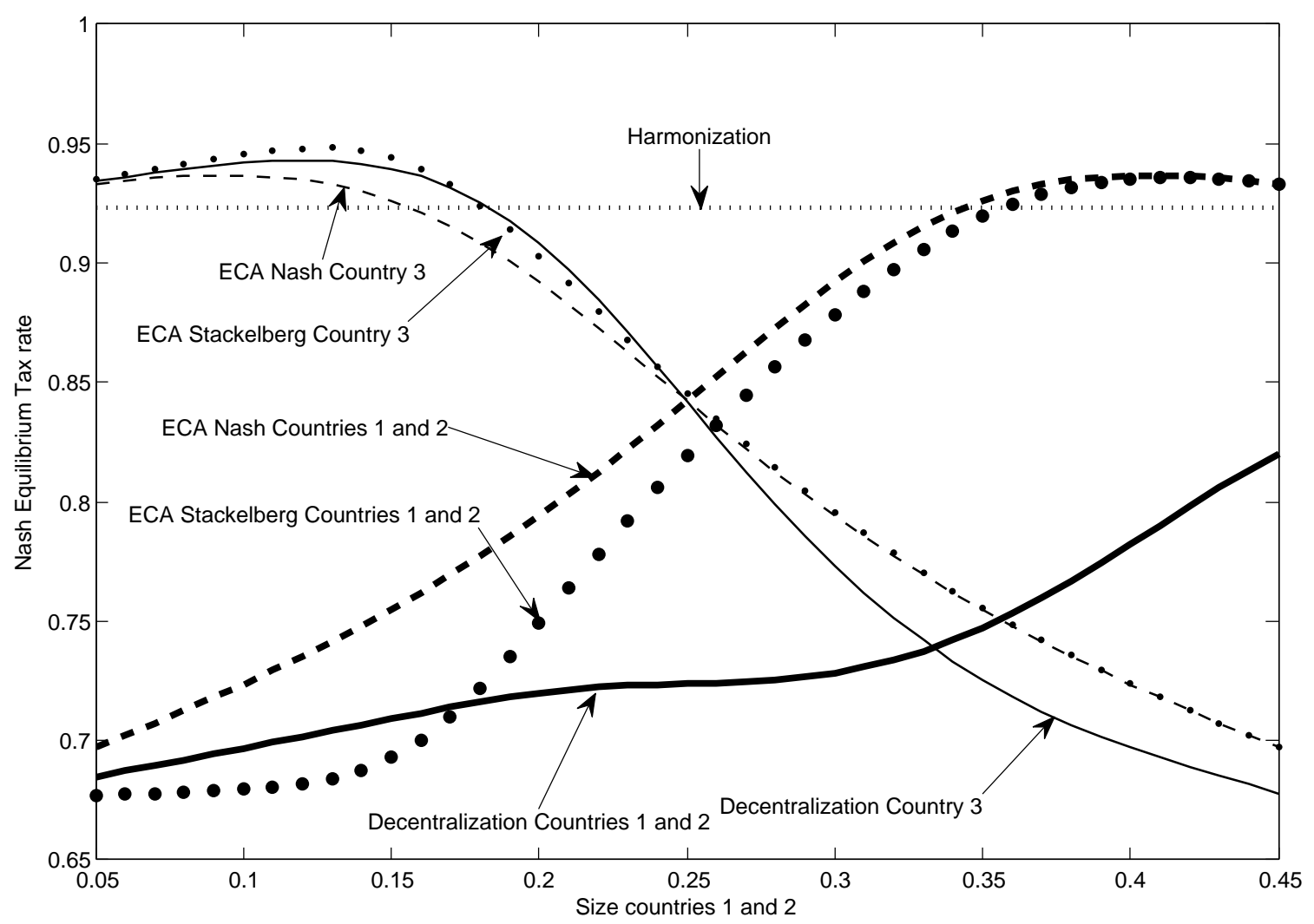

1 and 2 have a tendency to increase their tax rate, but country 3 has an incentive to reduce its rate, this worsens the tax rate differential from the perspective of countries 1 and 2 and results in a capital outflow. For $\sigma=1$, this capital outflow excerts a negative effect on the tax rate of countries 1 and 2. Accordingly, tax rates decrease in size over a certain range.

\subsection{ECA Nash}

ECA Nash tax rates in Figures (3) and (4) $\left(t_{u}^{N}\right.$ and $\left.t_{3}^{N}\right)$ are shown by the dashed lines. We see that these lines are symmetric in size around $s=0.25$. Indeed, if $s=0.25$ the ECA and country 3 are identical. When the relative size on either side changes, tax rates move symmetrically. Hence, tax competition under the ECA Nash regime merely comes down to competition between two countries, where the size of the ECA is determined by the joint size of countries 1 and 2 . 
Figure 4: Equilibrium tax rates under four regimes, $\sigma_{G C}=1$

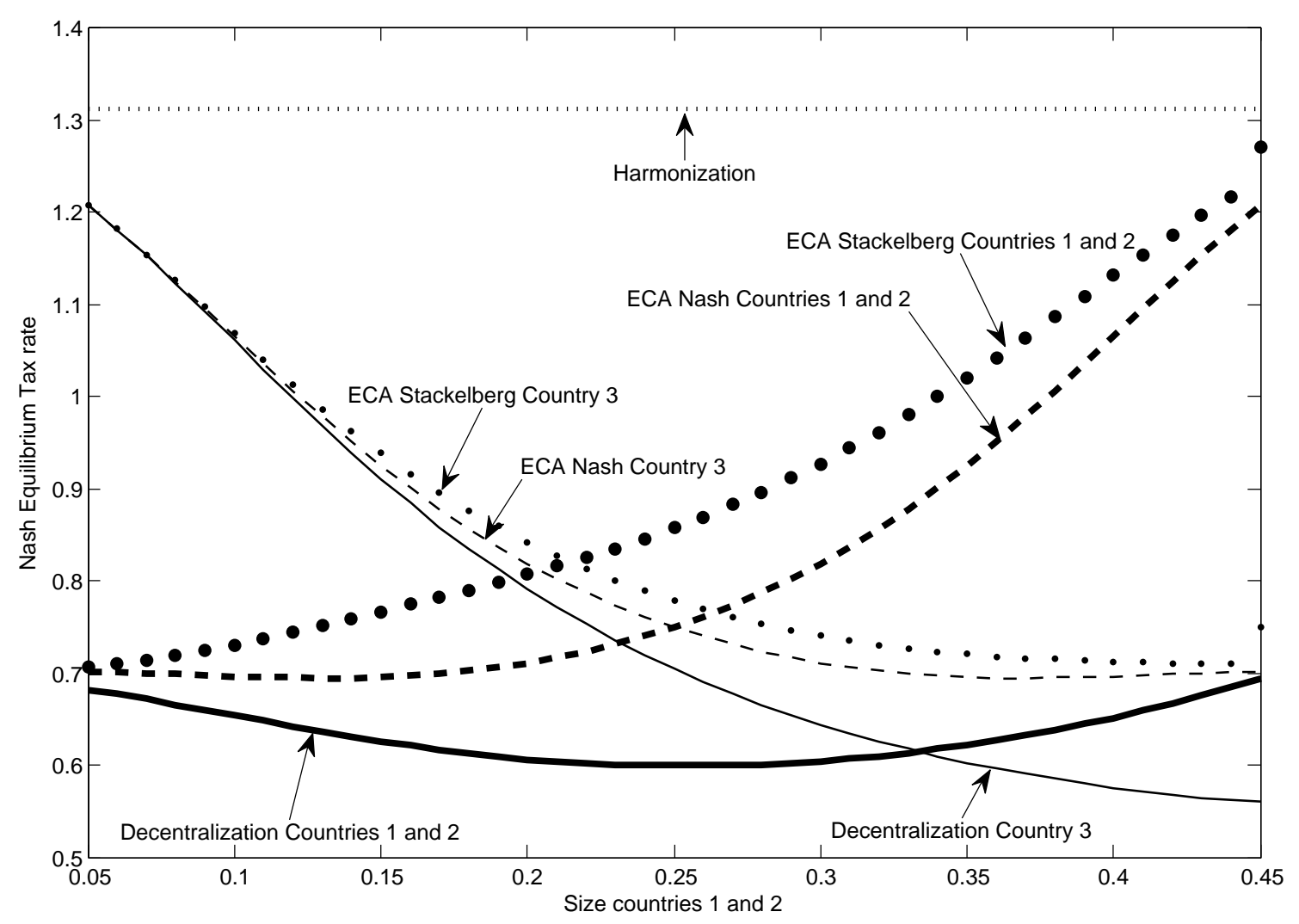

Figures (3) and (4) show that the ECA countries always set their tax rate higher under the ECA than under decentralization $\left(t_{i}^{N}>t_{i}^{D}\right.$ for $\left.i=1,2\right)$. This is for two reasons. First, the ECA reduces the tax elasticity of capital since spillovers between countries 1 and 2 are eliminated $\left(\epsilon_{K, i}^{N}<\epsilon_{K, i}^{D}\right.$ for $\left.i=1,2\right)$. Second, the ECA increases the tax rate elasticity of the interest rate $\left(\epsilon_{R, i}^{N}>\epsilon_{R, i}^{D}\right.$ for $\left.i=1,2\right)$. If the ECA countries are small, they are net capital importers. In that case, both changes in the elasticities reduce the $M C F$ so that ECA countries set a higher tax rate. If ECA countries are large, they are net capital exporters. In that case, the larger interest elasticity raises the $M C F$ and thus offsets the effect of the lower capital elasticity. Nevertheless, the effect of a lower tax elasticity of capital dominates so that we always find a higher tax rate by the ECA countries. In fact, the difference between $t^{N}$ and $t^{D}$ increases in the size of the ECA countries. This is because size magnifies the fiscal 
externality among the two ECA countries, relative to the fiscal externality vis a vis country 3 . The gains from internalizing the intra-ECA fiscal externality is therefore relatively important.

Figure (4) shows that, if $\sigma_{g c}=1$, country 3 will always set its tax rate above the decentralized rate, i.e. $t_{3}^{N}>t_{3}^{D}$. This is because the tax reaction function of country 3 is upward-sloping, i.e. the tax of country 3 is a strategic complement (see Figure (2)). As the ECA countries increase their tax rate by more if they are larger (i.e. if we move more to the right in Figure (4)), we see that this also induces a larger tax increase by country 3.

In Figure (3), where $\sigma_{g c}=0.1$, we see that the ECA-Nash tax in country 3 exceeds the decentralized rate only if $s>0.25$. If $s<0.25$, we have $t_{3}^{N}<t_{3}^{D}$. These results suggest that the tax rate of country 3 is characterized by strategic substitutability for $s<0.25$, but they should be interpreted with care as the tax reaction function can be U-shaped for $\sigma_{g c}=0.1$ (see Figure (1)). Therefore, to be more accurate, the shift of the equilibrium taxes reflect that the slope of the tax reaction function of country 3 is on average downward-sloping when moving from $t_{3}^{D}$ to $t_{3}^{N}$ as long as $s<0.25 .8$

\subsection{ECA Stackelberg}

Dotted lines in Figures (3) and (4) show the equilibrium tax rates under ECA-Stackelberg. Compared to the ECA-Nash equilibrium, the ECA countries now internalize the strategic response by country 3. Figure (4) (with $\sigma_{g c}=1$ ) reveals that the ECA countries always set a higher tax under Stackelberg leadership than under Nash or decentralization (i.e. $t_{u}^{S}>t_{u}^{N}>$ $t_{i}^{D}$ for $\left.i=1,2\right)$. Intuitively, the tax rate in country 3 is always a strategic complement on the margin if $\sigma_{g c}$ is large enough, so that $\partial t_{3} / \partial t_{u}>0$. Accordingly, the ECA countries realize that the equilibrium capital response to an increase in the tax is smaller, as country 3 will also increase its tax. This induces them to set a higher tax rate.

In Figure (3) (with $\sigma_{g c}=0.1$ ), the results are less clear-cut as the low value of $\sigma_{g c}$ allows for strategic substitutability. In particular, Figure (3) shows that the tax rate in the ECA countries under Stackelberg is always below the Nash tax rate, i.e. $t_{u}^{S}<t_{u}^{N}$. This is due

\footnotetext{
${ }^{8}$ For one part, the shift reflects strategic complementarity (i.e. $\frac{\partial t_{3}}{\partial t_{u}}>0$ ) of country $3^{\prime}$ s tax rate at the margin, when evaluated at the decentralization equilibrium. For another part, the slope of the tax reaction of country 3 may have adjusted as the equilibrium changes. Therefore, the shift also reflects strategic substitutability (i.e. $\frac{\partial t_{3}}{\partial t_{u}}<0$ ) of country $3^{\prime}$ s tax rate at the margin, when evaluated at the decentralization equilibrium.
} 
to strategic substitutability at the margin when evaluated at the ECA-Nash equilibrium, i.e. $\partial t_{3} / \partial t_{u}<0$. This seems at odds with the observation from Figure (3) that country3's ECA-Nash tax rates are above the equilibrium tax rates under decentralization for $s>0.25$. However, recall that the observed strategic response by country 3 reflects that slope of the tax reaction function of country 3 is upward-sloping on average when moving from $t_{3}^{D}$ to $t_{3}^{N}$. Under Stackelberg, the ECA countries are only interested in the strategic response by country 3 at the margin.

Figure (3) shows that, for $s<0.17$, the ECA-Stackelberg rate is even lower than the rate under decentralization $\left(t_{u}^{S}<t_{i}^{D}\right.$ for $\left.i=1,2\right)$. To understand this result, recall that relative to the optimal tax rule under decentralization, the optimal tax rule for ECA countries under Stackelberg internalizes both the strategic tax response by country 3 and within ECA spillovers. When ECA countries are small, the internalized spillovers are small and the expected strategic substitutability of the tax rate of country 3 dictates the policy rule. If the size of ECA countries grows both the size of internalized spillovers grows, and the likelihood of strategic complementarity on behalve of country 3 increases. Both give the ECA countries an incentive to increase the tax rate.

\section{Comparing welfare between tax regimes}

This section compares the welfare levels across the four different coordination regimes. To that end, we compute the utility level of households for the specifications chosen in the simulation exercises before. As in the previous section, we look at a continuum of size configurations. The relations between country size, welfare and the tax regime are presented in Figures (5) and (6) for, respectively $\sigma_{g c}=0.1$ and $\sigma_{g c}=1$. The horizontal lines in Figures (5) and (6) reflect the welfare levels under the first-best harmonized regime in which there are no distortions $\left(U_{i}^{H}\right)$. This regime maximizes global welfare. 
Figure 5: Welfare under four regimes, $\sigma_{G C}=0.1$

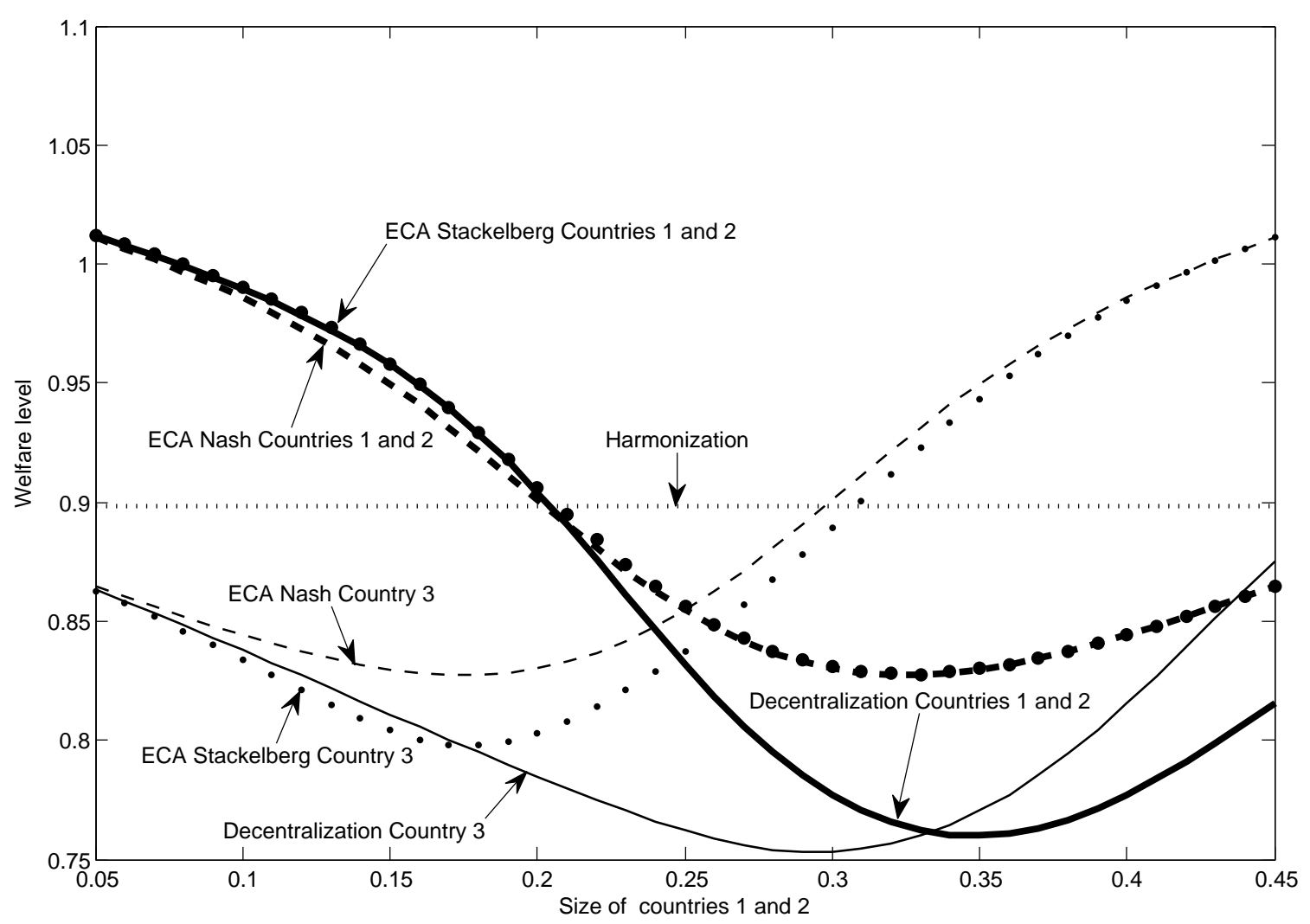

\subsection{Decentralization}

Solid lines in Figures (5) and (6) reflect the utility levels under decentralization $\left(U_{i}^{D}\right)$. We see that, if $s=0.33$, utility is equal in the three countries. The level of welfare is lower than under harmonization $\left(U_{i}^{D}<U_{i}^{H}\right)$ due to the underprovision of public goods. If countries differ in size, global welfare under decentralization is reduced further as different rates of tax distort the international allocation of capital. This reduces the world interest rate and further harms global welfare. The welfare cost of tax competition is not equally divided among countries. Comparing the two solid lines, we see that the welfare level in the smaller country exceeds the welfare level in the larger country. In fact, welfare under tax competition in the small country may even exceed the welfare under harmonization if a country becomes sufficiently small $\left(U_{i}^{D}>U_{i}^{H}\right.$ for $s_{i}$ sufficiently small). There are two offsetting effects responsible for this. On the one hand, small countries set a lower tax rate under decentralization compared 
Figure 6: Welfare under four regimes $\sigma_{G C}=1$

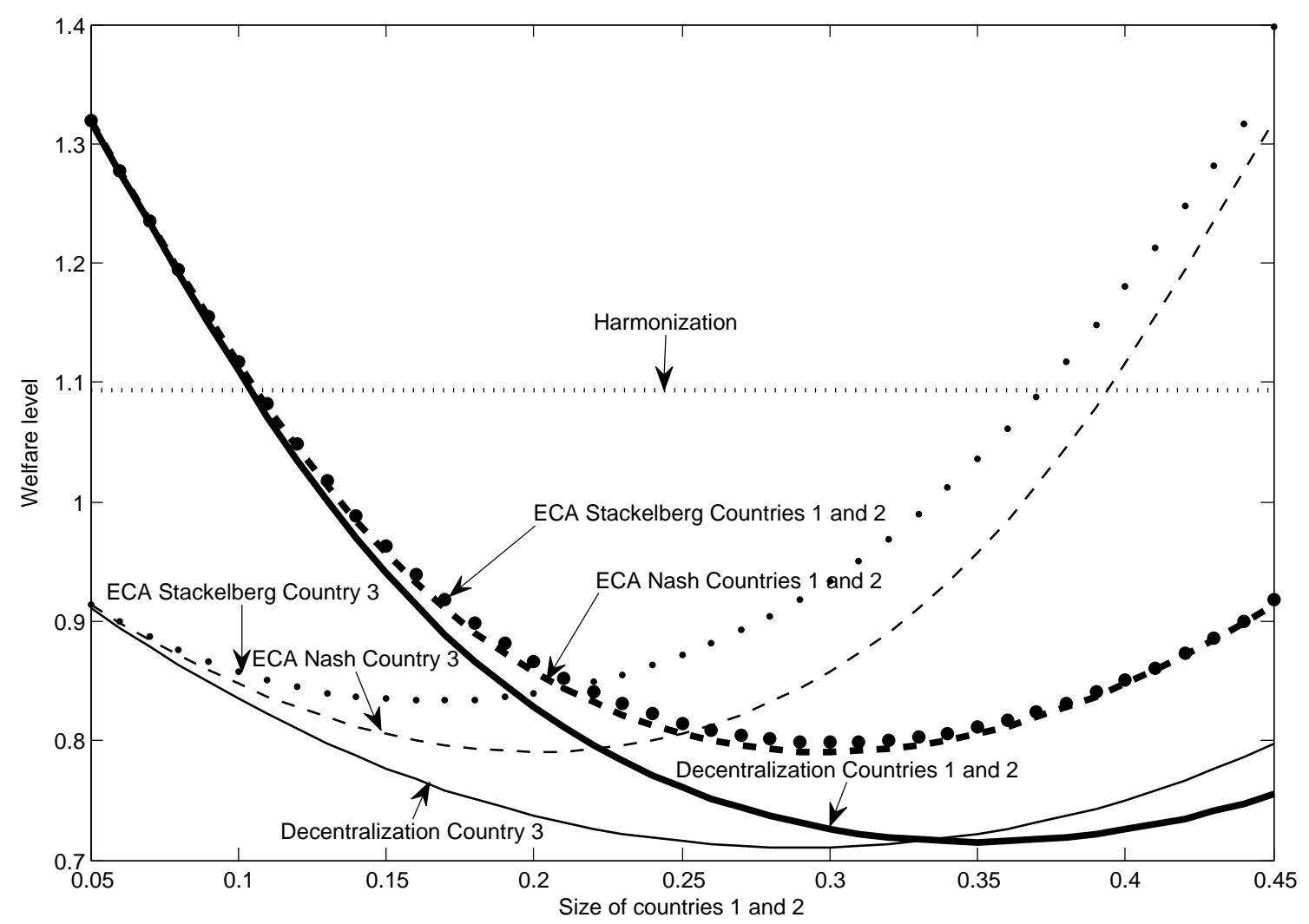

to harmonization as their taxes are highly distortive. This low tax yields an underprovision of public goods, resulting in lower welfare. On the other hand, the low tax rate benefits welfare in the small country due to an inflow of capital from the large country. For sufficiently small size, these benefits exceed the cost of underprovision of public goods. In the large country, welfare is always lower as it suffers a welfare loss from both an undersupply of public goods and an outflow of capital. The asymmetry in welfare effects explains why some countries are reluctant to cooperate in tax harmonization initiatives.

\subsection{ECA Nash}

Dashed lines in Figures (5) and (6) show the welfare levels under the ECA Nash regime $\left(U_{i}^{N}\right)$. If $\sigma_{g c}=1$, Figure (6) shows that welfare levels are always higher due to the ECA, both for the ECA countries and for the outside country, i.e. $U_{i}^{N}>U_{i}^{D}$ for $i=u, 3$. The reason is 
that the ECA countries internalize the fiscal spillovers among each other. Hence, the $M C F$ declines, so that countries set higher tax rates. By collecting more public revenue, they are able to mitigate the underprovision of public goods, which raises welfare. This welfare gain is more substantial when the ECA countries are large. In that case, intra-ECA spillovers are important and offer a high potential for welfare improvements. The tax increase by the ECA countries also raises welfare in country 3 due to an inflow of capital in that country. This broadens the capital tax base in country 3, thereby reducing the $M C F$ which mitigates the underprovision of public goods. Moreover, the tax in country 3 is a strategic complement with the tax in the ECA such that the capital flow out of the ECA countries is tempered, this raises welfare in the ECA countries. The welfare gain in both the ECA and country 3 is thus related to strategic complementarity. As in Konrad and Schjelderup (1999), it ensures that country 3 does not destroy the welfare gain in the ECA countries by more aggressively competing for capital. Under strategic complementarity, the formation of an ECA may thus find approval by both the ECA members and the non-ECA members.

In Figure (5) (where $\sigma_{g c}=0.1$ ), countries 1 and 2 benefit from the formation of an ECA only if $s>0.21$. For smaller $s$, welfare in the ECA countries is lower than under decentralization $\left(U_{u}^{N}<U_{u}^{D}\right)$. This is the outcome of two offsetting effects. On the one hand, a higher tax rate raises welfare by mitigating the underprovision of public goods in the ECA countries. On the other hand, a higher tax causes an outflow of capital. Although, the formation of the ECA mitigates this capital outflow, especially if the ECA countries are large, this effect depends on the response by country 3. With small $\sigma_{g c}$ and $s<0.25$, country 3 responds to the higher tax in the ECA countries by reducing its own rate (see previous section). This magnifies the outflow of capital from the ECA countries and reduces its welfare. Under ECA Nash, the ECA countries do not take this endogenous response by country 3 into account when deciding about their tax. Hence, it unexpectedly erodes their tax base and creates a welfare loss. For small $s$, this loss dominates the gains from removing intra-ECA spillovers. When $s>0.25$, country 3 responds to the higher tax in the ECA countries by increasing its tax rate. Moreover, with a larger size the welfare gains from 
internalizing intra-ECA spillovers is larger. Accordingly welfare under the ECA exceeds that under decentralization $\left(U_{u}^{N}>U_{u}^{D}\right)$.

Figure (5) shows that country 3 always benefits from the formation of the ECA $\left(U_{3}^{N}>\right.$ $\left.U_{3}^{D}\right)$. This broadens the capital tax base in country 3 , thereby reducing the $M C F$ which mitigates the underprovision of public goods.

Figures (5) and (6) show that small countries are better off under the ECA than under full harmonization $\left(U_{u}^{N}>U_{u}^{H}\right.$ for $s$ sufficiently small). Similarly, country 3 is better off under the ECA than under harmonization if it is sufficiently small, i.e. $U_{3}^{N}>U_{3}^{H}$ for $s$ sufficiently large. In general, small countries are neither interested in forming an ECA nor in full harmonization as they benefit from competition with the large country. Small countries gain, however, if two large countries form an ECA. For instance, in Figure (5) we see that welfare country 3 is highest under an ECA by the countries 1 and 2, then under full harmonization, and lowest under decentralization: $U_{3}^{N}>U_{3}^{H}>U_{3}^{D}$. Hence, opening up the possibility to form of an ECA may prevent country 3 from joining in a global harmonization agreement. Indeed, Figures (5) and (6) reveal that global harmonization is preferred by all countries only when countries are of similar size.

\subsection{ECA Stackelberg}

Dotted lines in Figures (5) and (6) reveal the welfare levels under the ECA Stackelberg regime $\left(U_{i}^{S}\right)$. We see that welfare under Stackelberg in the ECA countries is always higher than in both the decentralized outcome and the ECA-Nash outcome, i.e. $U_{u}^{S}>U_{u}^{N}$ and $U_{u}^{S}>U_{u}^{D}$. Hence, potential welfare losses under strategic substitutability with the ECA Nash regime disappear. The reason is that the ECA countries choose the welfare maximizing tax policy, thereby internalizing the strategic tax response by the outside country. Indeed, if the tax in country 3 is a strategic substitute, the ECA countries will increase their tax rates by less. This mitigates the outflow of capital, which benefits their welfare.

In Figure (6), we see that welfare in country 3 is always higher under ECA-Stackelberg than under ECA-Nash, i.e. $U_{3}^{S}>U_{3}^{N}$. Under strategic complementarity, both the ECA countries and country 3 choose higher tax rates and thus achieve a more efficient level of public 
goods. In Figure (5), however, tax rates are strategic substitutes. Under ECA-Stackelberg, this mitigates the tax increase by the ECA countries. Accordingly, country 3 sets a higher tax than under ECA-Nash. As a result, it suffers from a lower capital stock and its citizens are worse off than under ECA-Nash $U_{3}^{S}<U_{3}^{N}$.

\section{Conclusion}

This paper studies how in an asymmetric three country tax competition model, enhanced cooperation between two countries affects the equilibrium tax rates and welfare levels. Using both analytical and simulation analysis, we obtain the following results.

First, tax rates do not necessarily increase in country size in general equilibrium. The increase in country size gives an incentive to increase the tax rate. But simultaneously, the size of competing countries is reduced which gives them an incentive to reduce their rates. This results in a deterioration of the tax rate differential and an outflow of capital from the perspective of the former country. The outflow of capital gives an incentive to reduce the tax rate.

Second, while decentralized tax rates under tax competition are usually lower than harmonized rates, this is not necessarily the case for large countries. As tax competition erodes tax bases, large countries may want to compensate for this revenue loss by setting rates above those under harmonization. Public goods supply will still be lower for the large country, despite a higher tax.

Third, the formation of an ECA always leads to a higher tax in ECA countries. This is because the ECA reduces the marginal cost of public funds as it mitigates intra-ECA spillovers via capital flows.

Fourth, tax rates in different countries can be strategic complements or strategic substitutes, depending on country size and substitution possibilities between public and private consumption. Strategic complementarity is more likely if substitution between public and private consumption is easy, and if the outsider country is both small and a net capital im- 
porter. Strategic tax responses play a crucial role for both equilibrium tax rates and the welfare effects of an ECA.

Fifth, if ECA countries act as a Stackelberg leader, they tend to increase their rate more than under Nash if tax rates are strategic complements. Yet, they increase their rates less if tax rates are strategic substitutes.

Sixth, small countries are better off under decentralization compared to harmonization. This may cause a status quo in which countries will never agree upon harmonization. However, small countries may gain from forming an ECA with other small countries, although this is not guaranteed. Indeed, under Nash, they may be worse off due to the formation of an ECA as they are naive about the response in the outside country. This only holds when ECA countries are small and tax rates are strategic substitutes. The outsider country always gains when two other countries form an ECA under Nash.

Seventh, an ECA never reduces welfare if the ECA countries act as a Stackelberg leader. This is because they take the response by the outside country into account when deciding about their tax. Welfare in the outside country may be lower than under Nash, however, when tax rates are strategic substitutes.

Eighth, ECA countries may prefer the ECA over global harmonization when they are small relative to the outside country.

Ninth, non-ECA countries may prefer the formation of an ECA by other countries over both full harmonization and decentralization. This holds especially when the non-ECA country is small. Hence, the opportunity to form an ECA may hamper agreements on full harmonization. Only if countries are sufficiently similar in terms of size will global harmonization be preferred over an ECA.

In future research we aim to generalize our results in different settings. For instance, ECA among countries with more complex corporate taxation systems and ECA among asymmetric countries. This may not allow us to obtain analytical results, but may nevertheless shed light on the robustness of our findings in more realistic settings. 


\section{Appendix A: Deriving elasticities under four regimes}

This appendix derives the elasticities reported in Table (1). The elasticities under harmonization directly follow from the assumptions in the model. Under decentralization, we consider how a change in the tax rate in country $i$ affects the capital stock in countries $i$ and $j$.

$$
\begin{gathered}
\frac{\partial k_{i}}{\partial t_{i}}=\frac{1}{f_{i}^{\prime \prime}(.)}\left[1+\frac{\partial \rho}{\partial t_{i}}\right], \\
\frac{\partial k_{j}}{\partial t_{i}}=\frac{1}{f_{j}^{\prime \prime}(.)}\left[\frac{\partial \rho}{\partial t_{i}}\right],
\end{gathered}
$$

From Eq. (5) it follows that the total size of the capital stock is fixed, therefore:

$$
s_{i} \frac{\partial k_{i}}{\partial t_{i}}=-s_{j} \frac{\partial k_{j}}{\partial t_{i}}-s_{k} \frac{\partial k_{k}}{\partial t_{i}}
$$

Combining Eq. A.1, A.2 and A.3 we obtain:

$$
\frac{\partial k_{i}}{\partial t_{i}} \frac{t_{i}}{k_{i}}=\frac{t_{i}}{f_{i}^{\prime \prime}(.) k_{i}}\left[\frac{s_{j}\left(1 / f_{j}^{\prime \prime}(.)\right)+s_{k}\left(1 / f_{k}^{\prime \prime}(.)\right)}{s_{i}\left(1 / f_{i}^{\prime \prime}(.)+s_{j}\left(1 / f_{j}^{\prime \prime}(.)\right)+s_{k}\left(1 / f_{k}^{\prime \prime}(.)\right)\right.}\right]=-\epsilon_{K, i}^{D}<0,
$$

The change in the interest rate follows from substituting Eq. (A.4) in (A.1):

$$
\frac{\partial \rho}{\partial t_{i}}=\frac{-s_{i}\left(1 / f_{i}^{\prime \prime}(.)\right)}{s_{i}\left(1 / f_{i}^{\prime \prime}(.)\right)+s_{k}\left(1 / f_{k}^{\prime \prime}(.)\right)+s_{j}\left(1 / f_{j}^{\prime \prime}(.)\right)}=-\epsilon_{R, i}^{D}<0
$$

Under an ECA, countries 1 and 2 form a union $(u)$, with: $k_{u}=k_{1}=k_{2}, f_{u}^{\prime \prime}()=.f_{1}^{\prime \prime}()=$. $f_{2}^{\prime \prime}($.$) and t_{u}=t_{1}=t_{2}$. The following two equations describe the capital market:

$$
\begin{aligned}
f_{i}^{\prime \prime}(.) \frac{\partial k_{i}}{\partial t_{i}}-1 & =f_{j}^{\prime \prime}(.) \frac{\partial k_{j}}{\partial t_{i}}, \\
s_{i} \frac{\partial k_{i}}{\partial t_{i}} & =-\left(1-s_{i}\right) \frac{\partial k_{j}}{\partial t_{i}},
\end{aligned}
$$

where $i$ and $j \in\{u, 3\}$, and $s_{u}=2 s$ and $s_{3}=(1-2 s)$. This yields:

$$
\frac{\partial k_{i}}{\partial t_{i}} \frac{t_{i}}{k_{i}}=\frac{t_{i}}{f_{i}^{\prime \prime}(.) k_{i}}\left[\frac{s_{j}\left(1 / f_{j}^{\prime \prime}(.)\right)}{s_{i}\left(1 / f_{i}^{\prime \prime}(.)+s_{j}\left(1 / f_{j}^{\prime \prime}(.)\right)\right.}\right]=-\epsilon_{K, i}^{N}<0
$$


Substituting back into Eq. A.5, we obtain:

$$
\frac{\partial \rho}{\partial t_{i}}=\frac{-s_{i}\left(1 / f_{i}^{\prime \prime}(.)\right)}{s_{i}\left(1 / f_{i}^{\prime \prime}(.)\right)+s_{j}\left(1 / f_{j}^{\prime \prime}(.)\right)}=-\epsilon_{R, i}^{N}<0 .
$$

Under Stackelberg, we obtain the same elasticities as under Nash, but for the ECA countries add to this the expected response by the third country.

\section{Acknowledgements}

The authors thank Leon Bettendorf, Bas Jacobs, Joana Pereira and Floris Zoutman for helpful comments. We benefited from comments of seminar participants at the Tinbergen Institute, the NAKE Research Day and the IIPF conference in Cape Town.

\section{References}

Alesina, A., I. Angeloni, and F. Etro (2005): "International Unions," The American Economic Review, 95, 602-615.

BAyindir-Upmann, T., AND A. ZIAD (2005): "Existence of equilibria in a basic taxcompetition model," Regional Science and Urban Economics, 35, 1-22.

Beaudry, P., P. Cahuc, and H. Kempf (2000): "Is it Harmful to Allow Partial Cooperation?," Scandinavian Journal of Economics, 95, 1-21.

Bettendorf, L., A. van der Horst, R. A. de Mooij, and H. Vrijburg (2009): "Corporate Tax Consolidation and Enhanced Cooperation in the European Union," Cpb discussion paper no. 132, CPB, the Hague.

Bordignon, M., And S. Brusca (2006): "On enhanced cooperation," Journal of Public Economics, 90, 2063-2090.

Brøchner, J., J. Jensen, P. Svensson, and P. B. Sørensen (2006): "The dilemmas of Tax Coordination in the Enlarged European Union," Working paper, CESifo, Munich. 
Bucovetsky, S. (1991): "Asymmetric Tax Competition," Journal of Urban Ecnonomics, $30,167-181$.

Burbidge, J. B., J. A. DePater, G. M. Myers, and A. Sengupta (1997): "A CoalitionFormation Approach to Equilibrium Federations and Trading Blocs," The American Economic Review, 87, 940-956.

Konrad, K., And G. Schjelderup (1999): "Fortress building in global tax competition," Journal of Urban Economics, 46, 156-167.

Lockwood, B. (2004): "Competition in Unit vs. Ad Valorem Taxes," International Tax and Public Finance, 11, 763-772.

Manzini, P., And M. Mariotti (2002): "A "Tragedy of the Clubs": Excess Entry in Exclusive Coalitions," Journal of Public Economic Theory, 4, 115-136.

Riedel, N., And M. Runkel (2007): "Company tax reform with a water's edge," Journal of Public Economics, 91, 1533-1554.

Sørensen, P. B. (2000): "The case for international tax co-ordination reconsidered," Economic Policy, 31, 429-472.

- (2004): "Company tax reform in the European Union," International Tax and Public Finance, 11, 91-115.

Wilson, J. D. (1991): "Tax competition with interregional differences in factor endownments," Regional Science and Urban Economics, 21, 423-451. 